\title{
Mucinous and secondary tumors of the prostate
}

\author{
Adeboye O Osunkoya ${ }^{1,2,3,4}$ \\ ${ }^{1}$ Department of Pathology, Emory University School of Medicine, Atlanta, GA, USA; ${ }^{2}$ Department of Urology, \\ Emory University School of Medicine, Atlanta, GA, USA; ${ }^{3}$ Department of Pathology, Veterans Affairs Medical \\ Center, Atlanta, GA, USA and ${ }^{4}$ Winship Cancer Institute, Emory University, Atlanta, GA, USA
}

\begin{abstract}
Primary mucinous tumors and secondary tumors involving the prostate gland are relatively uncommon, however they have important diagnostic, therapeutic, and prognostic implications. The primary mucinous tumors of the prostate include mucinous (colloid) adenocarcinoma of the prostate, prostatic adenocarcinoma with mucinous features, and mucinous adenocarcinoma of the prostatic urethra (mucin-producing urothelial-type adenocarcinoma of the prostate). Mucinous adenocarcinoma of the prostate is defined as a primary prostatic acinar tumor characterized by the presence of at least $25 \%$ of the tumor composed of glands with extraluminal mucin. This diagnosis can only be made in radical prostatectomy specimens. Recent studies have shown that these tumors have a similar or in some cases better prognosis than conventional prostatic adenocarcinoma treated by radical prostatectomy. The preferred terminology for tumors that are composed of $<25 \%$ extraluminal mucinous component in radical prostatectomy specimens is 'prostatic adenocarcinoma with mucinous features.' All cases of prostatic adenocarcinoma with extraluminal mucinous components in prostate needle core biopsies or transurethral resection of the prostate specimens are also referred to as 'prostatic adenocarcinoma with mucinous features.' Mucinous adenocarcinoma of the prostatic urethra (mucin-producing urothelial-type adenocarcinoma of the prostate) as the name implies, does not arise from prostatic acini or ducts, and is a distinct entity that arises from the prostatic urethra usually from urethritis glandularis or glandular metaplasia with malignant transformation, and is analogous to adenocarcinoma with mucinous differentiation arising from the urinary bladder. This tumor is aggressive and has a relatively poor prognosis. The most common secondary tumors that arise from adjacent organs and spread (direct extension or metastasis) to the prostate gland, include urothelial carcinoma of the bladder and colorectal adenocarcinoma. Other secondary tumors that may involve the prostate include metastatic epithelial tumors from several other sites, malignant melanoma and soft tissue tumors.
\end{abstract}

Modern Pathology (2018) 31, S80-S95; doi:10.1038/modpathol.2017.132

\section{Introduction}

Our understanding of primary mucinous tumors and secondary tumors involving the prostate gland has increased over the past few decades, due to more careful and detailed gross and microscopic examinations, increased utility of immunohistochemical stains, biomarkers, and molecular diagnostics. The primary mucinous tumors involving the prostate gland include mucinous (colloid) adenocarcinoma of the prostate, prostatic adenocarcinoma with mucinous features, and

Correspondence: Professor AO Osunkoya, MD, Department of Pathology, Emory University School of Medicine, Suite H174, 1364 Clifton Road, NE, Atlanta, GA 30322, USA.

E-mail: adeboye.osunkoya@emory.edu

Received 14 June 2017; revised 3 August 2017; accepted 3 August 2017 mucinous adenocarcinoma of the prostatic urethra (mucin-producing urothelial-type adenocarcinoma of the prostate). ${ }^{1-4}$ The most common secondary tumors that arise from adjacent organs and spread (direct extension or metastasis) to the prostate gland, include urothelial carcinoma of the bladder and colorectal adenocarcinoma. ${ }^{1,5-9}$ In view of the fact that some of these entities have overlapping features, in this brief review, the diagnostic features of each of these entities (and a few others) will be discussed from a practical standpoint, with emphasis on differential diagnoses and potential diagnostic pitfalls.

\section{Mucinous adenocarcinoma of the prostate}

Mucinous adenocarcinoma of the prostate (previously referred to as colloid carcinoma of the 

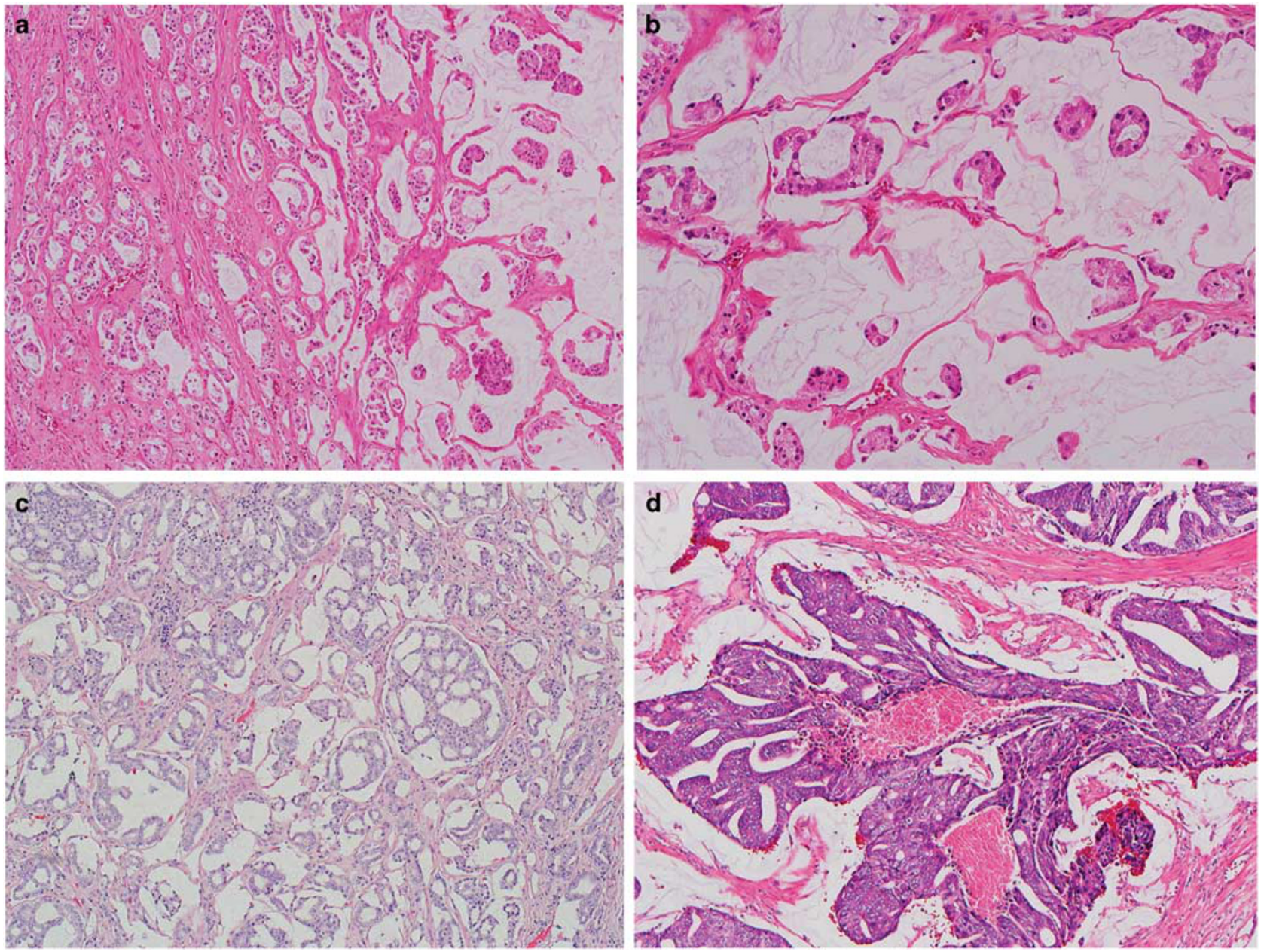

Figure 1 (a) Mucinous adenocarcinoma of the prostate. Mucinous component is predominantly composed of well-formed glands (Gleason score $3+3=6 /$ Grade group 1). (b) Mucinous adenocarcinoma of the prostate (higher magnification). Mucinous component is predominantly composed of well-formed glands (Gleason score $3+3=6 /$ Grade group 1). (c) Mucinous adenocarcinoma of the prostate. Mucinous component is predominantly composed of cribriform glands (Gleason score 4+4=8/Grade group 4). (d) Mucinous adenocarcinoma of the prostate. Mucinous component is predominantly composed of cribriform glands with necrosis (Gleason score $5+4=9 /$ Grade group 5).

prostate) is a rare morphological variant of prostate cancer. The incidence of mucinous adenocarcinoma of the prostate, defined by the presence of at least $25 \%$ of the tumor composed of glands with extraluminal mucin (Figures 1a-d), is $\sim 0.2 \% .{ }^{1-3,10,11}$ The presence of intraluminal mucin (Figures 2a and b), seen in up to one-third of prostatic adenocarcinomas, should not be referred to as mucinous adenocarcinoma of the prostate or prostatic adenocarcinoma with mucinous features. In addition, primary mucinous tumors arising from the prostatic urethra or secondary tumors from other sites/organs must be excluded ${ }^{2}$

In the past, it was debatable whether to assign a Gleason score to these tumors. In addition, at some point several years ago, some pathologists assumed that all cases of mucinous adenocarcinoma of the prostate should be assigned a high Gleason score. Recent data support grading mucinous adenocarcinoma of the prostate on the basis of the underlying architectural pattern (well-formed glands: Gleason grade 3, poorly formed glands: Gleason grade 4, cribriform glands: Gleason grade 4, single cells: Gleason grade 5, etc) rather than assuming that all of these tumors are aggressive (Figures 1a-d).,12,13 Data from recent large studies have also demonstrated that mucinous adenocarcinoma of the prostate treated by radical prostatectomy is not more aggressive than usual non-mucinous prostatic adenocarcinoma, and may potentially be even less aggressive. ${ }^{1,3,10-13}$ This is in contrast to older studies that assumed that most of these tumors were aggressive (or were inconclusive). ${ }^{14-16}$

In the study by Lane et al ${ }^{12}$ they analyzed the clinicopathologic and prognostic features of 14 patients with mucinous prostatic adenocarcinoma with a median follow-up of 6.4 years. No patients with mucinous prostatic adenocarcinoma or prostatic adenocarcinoma with mucinous features died of disease, and 11/12 (91.7\%) patients with 

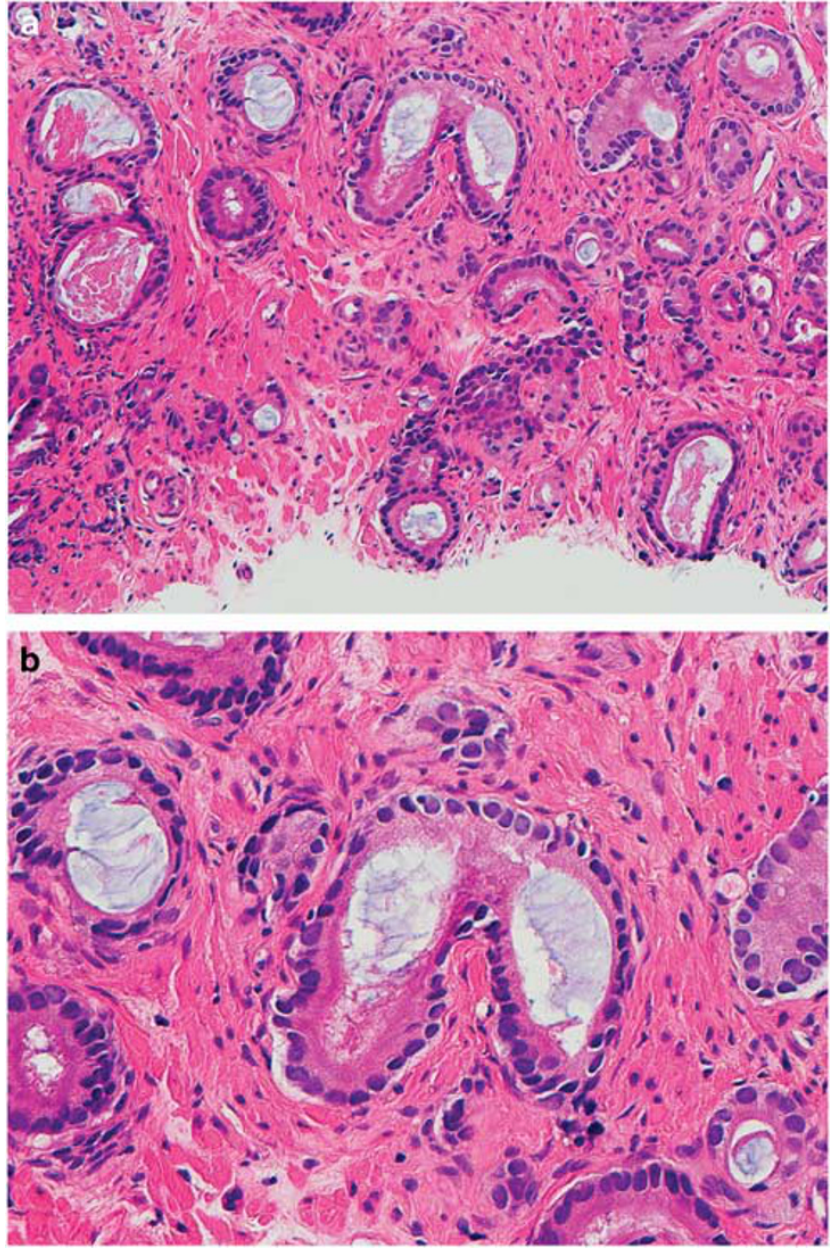

Figure 2 (a) Conventional prostatic adenocarcinoma with intraluminal mucin. Needle core biopsy $(\times 20$ magnification). (b) Conventional prostatic adenocarcinoma with intraluminal mucin. Needle core biopsy ( $\times 40$ magnification).

mucinous prostatic adenocarcinoma and 9/14 $(64.3 \%)$ patients with prostatic adenocarcinoma with mucinous features had no biochemical recurrence. ${ }^{12}$ In addition, no significant difference was found in overall survival or biochemical recurrence between patients with mucinous prostatic adenocarcinoma or prostatic adenocarcinoma with mucinous features and a matched group of patients with conventional prostatic adenocarcinoma. They concluded that mucinous prostatic adenocarcinoma does not confer poor prognosis. ${ }^{12}$ Similarly, in the study by Osunkoya et $a l^{3}{ }^{3} 47$ patients with mucinous prostatic adenocarcinoma treated with radical prostatectomy had more favorable outcomes relative to those with conventional prostatic adenocarcinoma comparing grade and stage. The mean 5-year actuarial PSA progressionfree risk rate was $97.2 \%$ for patients with mucinous prostatic adenocarcinoma, compared with the predicted mean 5-year progression-free risk of $85.4 \%$ for patients with conventional prostatic adenocarcinoma with the same PSA and postoperative findings. ${ }^{3}$

Over the years, our understanding of the pathogenesis and significance of extraluminal mucin production in mucinous prostatic adenocarcinoma has increased. Mucinous prostatic adenocarcinoma has been shown to express MUC2 (goblet-type, secretorytype, or gel-forming-type mucin), which has been found to form strong bonds with the stroma and likely has pathologic and prognostic significance. ${ }^{17}$ Overexpression or ectopic expression of MUC2 has also been reported in mucinous (colloid) adenocarcinomas of other organs/sites such as the pancreas, breast, skin, and ovary. ${ }^{18}$ Therefore, there is likely a common genetic alteration shared by mucinous adenocarcinomas of various organs including the prostate with relation to MUC2 expression leading to mucinous differentiation. ${ }^{17}$ In a study of colloid carcinomas of the breast and pancreas, it appeared that inverse polarization of the surface glycoproteins and secretory organelles directed toward the stromal aspect of the cells in conjunction with a lack of basal cell formation allows for the secretion of mucin toward the stroma and the accumulation of extracellular mucin. ${ }^{18}$ In a study of 25 cases of mucinous prostatic adenocarcinoma and 25 cases of conventional prostatic adenocarcinoma, all cases of mucinous prostatic adenocarcinoma had variably positive expression of MUC2, and only 6 of 25 cases of conventional prostatic adenocarcinoma had positive MUC2 expression. ${ }^{17}$ Not only does MUC2 contribute to the morphology of mucinous adenocarcinomas, but it may also be a biological factor in the relatively slow growth of these tumors. ${ }^{17,18}$ It has also been hypothesized that the extracellular mucin associated with mucinous (colloid) carcinoma, which accumulates in the stroma and surrounds the neoplastic cells, actually interferes with their ability to spread. ${ }^{18}$

Loss of PTEN expression is known to occur in aggressive high-grade prostatic adenocarcinoma. ${ }^{19-23}$ Bertsch et $a 1^{24}$ analyzed PTEN expression in 92 cases of mucinous prostatic adenocarcinoma (34 cases) and prostatic adenocarcinoma with mucinous features (58 cases). PTEN expression was positive in the mucinous component of $79 / 92(86 \%)$ cases. The fact that $86 \%$ of cases of mucinous prostatic adenocarcinoma and prostatic adenocarcinoma with mucinous features were positive for PTEN despite relatively high Gleason scores ( $>50 \%$ of cases were $4+3=7$ or higher), may give some insight into why a number of these tumors may be less aggressive than conventional prostatic adenocarcinoma without associated extraluminal mucinous components. ${ }^{24}$

\section{Prostatic adenocarcinoma with mucinous features}

It is important to note that when prostatic adenocarcinoma with extraluminal mucin is present in a TURP specimen or needle core biopsies 

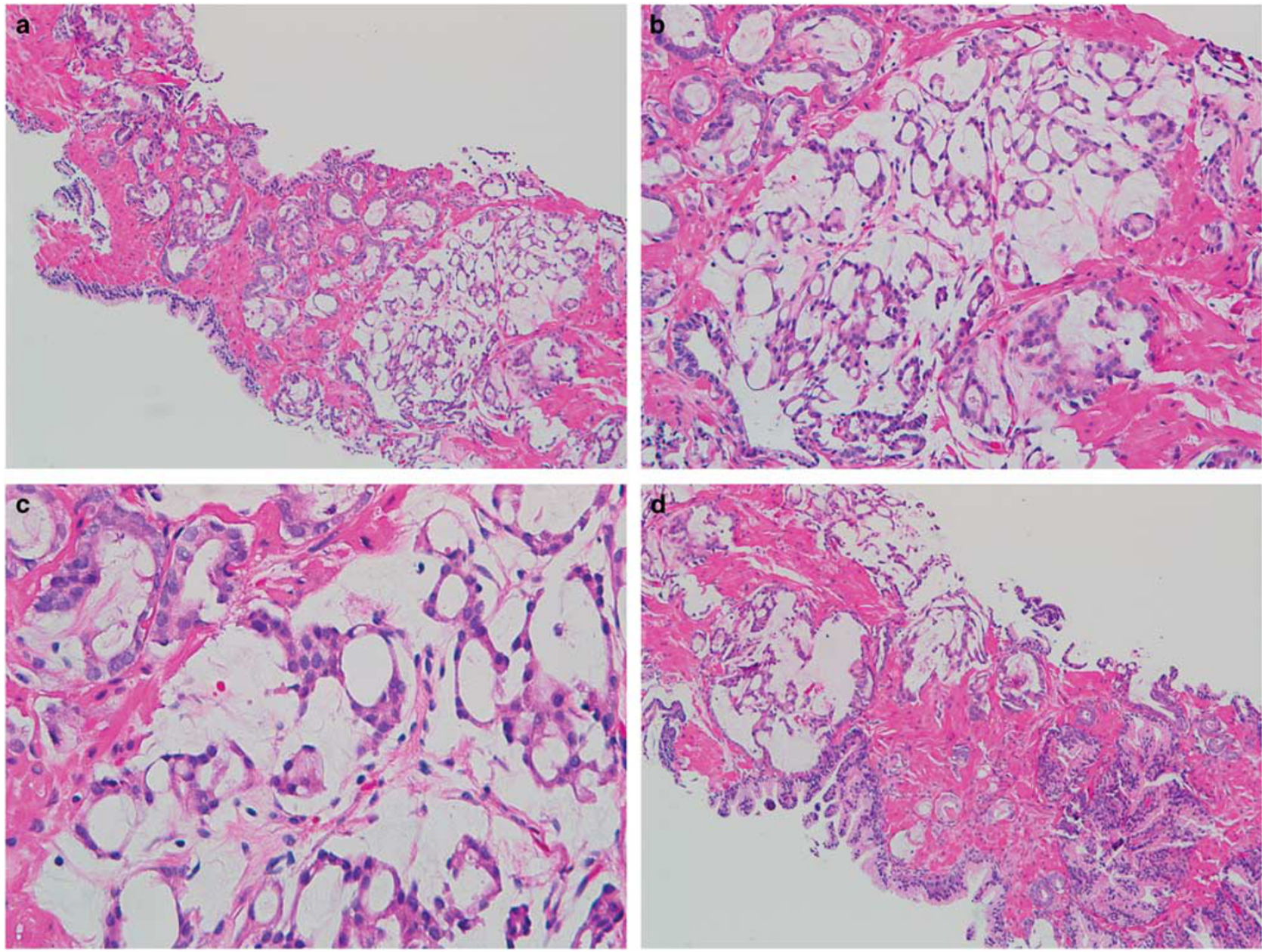

Figure 3 (a) Prostatic adenocarcinoma with mucinous features. Needle core biopsy $(\times 10$ magnification). (b) Prostatic adenocarcinoma with mucinous features. Needle core biopsy ( $\times 20$ magnification). (c) Prostatic adenocarcinoma with mucinous features. Needle core biopsy $(\times 40$ magnification). (d) Prostatic adenocarcinoma with mucinous features. Needle core biopsy (×10 magnification).

(Figures 3a-d), a diagnosis of 'Prostatic adenocarcinoma with mucinous features' should be rendered. This is due to the fact that the entire tumor (radical prostatectomy specimen) has to be present to confirm that the extraluminal mucinous component is indeed greater than $25 \%$ before a definitive diagnosis of mucinous adenocarcinoma of the prostate can be made. In addition, if the extraluminal mucinous component is $<25 \%$ in a radical prostatectomy specimen (Figures $4 \mathrm{a}$ and b), then a diagnosis of 'Prostatic adenocarcinoma with mucinous features' should also be rendered.

Interestingly, mucinous fibroplasia (one of the few pathognomonic features of prostate cancer) that is composed of delicate organization of collagen is occasionally intimately admixed with mucinous adenocarcinoma of the prostate and prostatic adenocarcinoma with mucinous features (Figures $5 \mathrm{a}-\mathrm{d}$ ). ${ }^{2,3}$

Similar to conventional acinar prostatic adenocarcinoma, markers such as PSA, PAP, PSMA, ERG, P501S, P504S, PTEN, etc are also variably expressed in mucinous adenocarcinoma of the prostate and prostatic adenocarcinoma with mucinous features. $25-29$

\section{Differential Diagnosis}

The main entities to consider in the differential diagnosis of mucinous adenocarcinoma of the prostate or prostatic adenocarcinoma with mucinous features are mucinous adenocarcinoma arising from the prostatic urethra (discussed below) or bladder, and colorectal adenocarcinoma involving the prostate (discussed below).

\section{Mucinous adenocarcinoma of the prostatic urethra (mucin-producing urothelial-type adenocarcinoma of the prostate)}

The prostatic urethra is an important component of the prostate gland and is primarily lined by urothelium. Urothelial metaplasia may however occur within the periurethral glands and prostatic ducts 

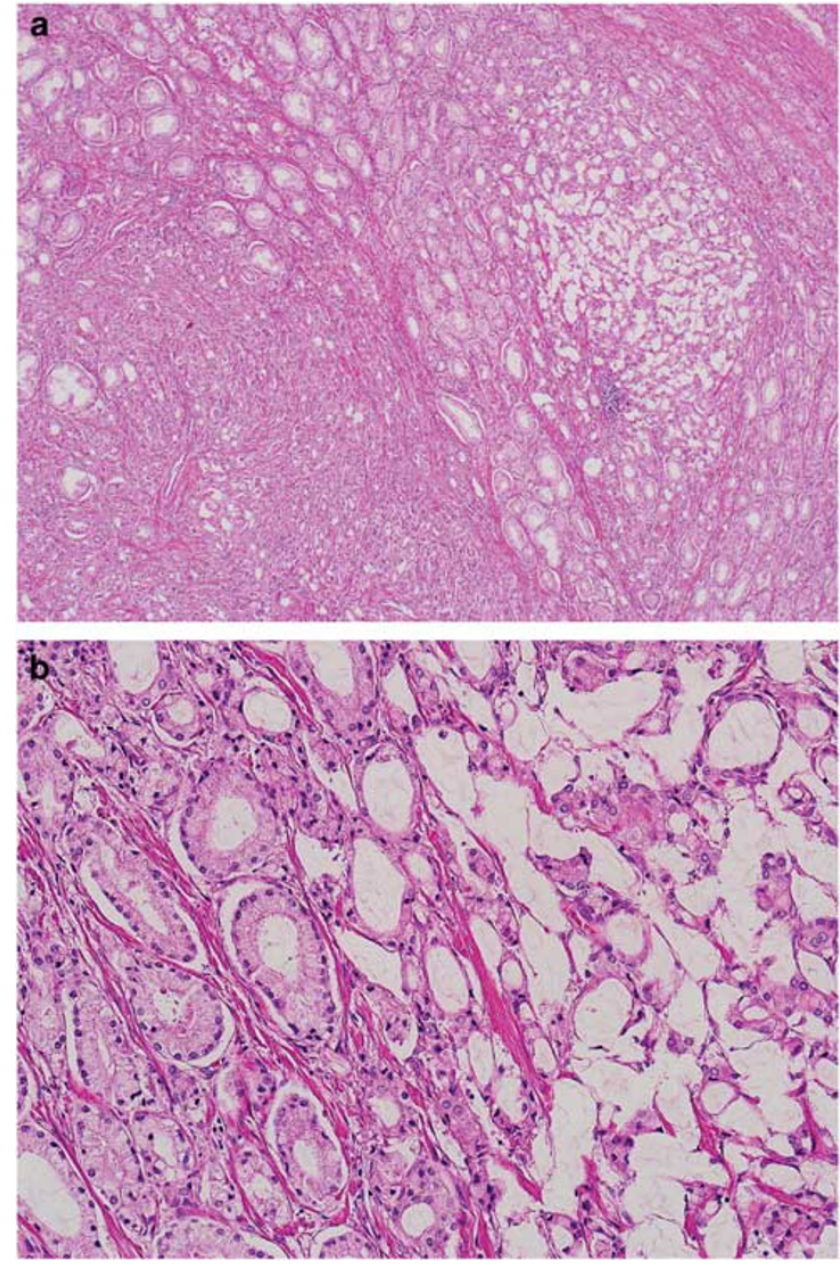

Figure 4 (a) Prostatic adenocarcinoma with mucinous features. Radical prostatectomy ( $\times 4$ magnification). (b) Prostatic adenocarcinoma with mucinous features. Radical prostatectomy $(\times 20$ magnification).

and acini. Urothelial tumors more commonly seen in the bladder that can also occasionally arise from the urothelium of the prostatic urethra include inverted urothelial papilloma, fibroepithelial polyp, and urothelial carcinoma. ${ }^{11}$

Mucinous adenocarcinoma of the prostatic urethra (also known as mucin-producing urothelial-type adenocarcinoma of the prostate) originates from urethritis glandularis or glandular metaplasia of the prostatic urethra with malignant transformation (Figures 6a-d), and is analogous to adenocarcinoma arising from the urinary bladder. ${ }^{30-34}$ In view of the fact that mucinous adenocarcinoma of the prostatic urethra is identical in its morphology and histogenesis to mucinous adenocarcinoma of the bladder, the latter must be excluded before this diagnosis is rendered. ${ }^{32}$

Mucinous adenocarcinoma of the prostatic urethra is characterized by large pools of mucin lined by pseudostratified or tall columnar cells with areas of mucin dissecting into the stroma forming pools (Figures $7 \mathrm{a}-\mathrm{C}$ ). The tumor may also occasionally demonstrate tubules or cribriform glands (mimicking prostatic adenocarcinoma with mucous features), and signet ring cells floating within pools of mucin may also be present (Figures 8a-c). Extensive perineural invasion is usually present, though in some cases/foci, only rare tumor cells with perineural invasion floating in pools of mucin may be seen (Figure 9) and in advanced cases, extraprostatic extension may also be present (Figures 10a and b).

In the largest series to date on this entity, the mean patient age at diagnosis was 72 years (range: 58-93 years) and the predominant mode of presentation was urinary obstruction. ${ }^{32}$ A relatively more specific finding seen in $20 \%$ of cases, which may also be seen with primary adenocarcinoma or villous adenoma of the bladder, is mucusuria. As expected (since the tumor arises from the prostatic urethra and not luminal cells of prostatic ducts or acini), the PSA levels in the series were not elevated with a mean of $0.91 \mathrm{ng} / \mathrm{ml}$ (range: $0.2-1.3 \mathrm{ng} / \mathrm{ml}$ ). All men had negative colonoscopies, clinically excluding a colorectal primary. Bladder primaries were ruled out clinically by cystoscopy or pathologically in radical cystoprostatectomy specimens. ${ }^{32}$ Follow-up was available on all men with a mean duration of 50.3 months (range: 2-161 months). Five men underwent radical prostatectomy, two cystoprostatectomy, one a pelvic exenteration, and seven were treated by TURP. Three of the men who had radical prostatectomy received radiation therapy with one of them also having chemotherapy. Two of the seven men who had TURP also received radiation therapy. Of the eight men with radical resections, the pathologic findings for the tumor were extraprostatic extension in eight, positive margins in four, and seminal vesicle invasion in four. ${ }^{32}$

Although mucinous adenocarcinoma of the prostatic urethra is an adenocarcinoma that involves the prostate, it should not be assigned a Gleason score (in contrast to mucinous adenocarcinoma of the prostate), as these tumors do not arise from prostatic ducts or acini-like prostatic adenocarcinoma from which the Gleason system was derived. In one-third of the cases in the largest series, a precursor lesion, such as urethritis glandularis or villous adenoma could not be identified. This finding most likely reflects either sampling issues or destruction of the surface component by infiltrating tumor.

Mucinous adenocarcinoma of the prostatic urethra is typically immunoreactive for CK7, CK20, CEA and negative for PSA, PSAP, NKX3.1 (Figures 11a-d). CDX2 is typically negative, but may demonstrate focal positivity especially in cases with enteric features. Interestingly, a similar entity involving the urethra in female patients has been recently described. ${ }^{35}$

\section{Differential Diagnosis}

The main entities to consider in the differential diagnosis of mucinous adenocarcinoma of the 



Figure 5 (a) Prostatic adenocarcinoma with mucinous features and extensive mucinous fibroplasia. Needle core biopsy $(\times 10$ magnification). (b) Prostatic adenocarcinoma with mucinous features and extensive mucinous fibroplasia. Radical prostatectomy $(\times 10$ magnification). (c) Prostatic adenocarcinoma with mucinous features and extensive mucinous fibroplasia. Radical prostatectomy $(\times 20$ magnification). (d) Prostatic adenocarcinoma with mucinous features and extensive mucinous fibroplasia. Radical prostatectomy ( $\times 40$ magnification).

prostatic urethra include colorectal adenocarcinoma involving the prostate (discussed below) and mucinous adenocarcinoma of the prostate (discussed above).

In summary, it is critical to make the distinction between mucinous adenocarcinoma of the prostatic urethra and mucinous adenocarcinoma of the prostate (once extraprostatic primaries have been excluded), not only to avoid rendering a Gleason score in the former, but also for therapeutic considerations, as hormonal (androgen deprivation) therapy would not be a treatment choice for mucinous adenocarcinoma of the prostatic urethra. In addition, cases of mucinous adenocarcinoma of the prostatic urethra may require radical cystoprostatectomy.

\section{Secondary tumors of the prostate}

Secondary tumors involving the prostate excluding those from direct extension from adjacent organs (bladder and colorectum) are rare. Metastasis from other sites to the prostate typically arise from the lung, upper gastrointestinal tract, skin (melanoma), kidney, testicle, endocrine organs, and others, with an incidence ranging from 0.1 to $6.0 \%$ depending on the series. ${ }^{36-57}$ In view of the proximity to the prostate, the most common secondary tumor involving the prostate though direct extension is from the urinary bladder. Colorectal tumors including colorectal adenocarcinoma and gastrointestinal stromal tumor (GIST) may also occasionally involve the prostate.

\section{Urothelial carcinoma of the bladder with involvement of the prostate}

A number of studies have described various patterns and mechanisms of prostatic involvement by urothelial carcinoma: urothelial carcinoma in situ of the 

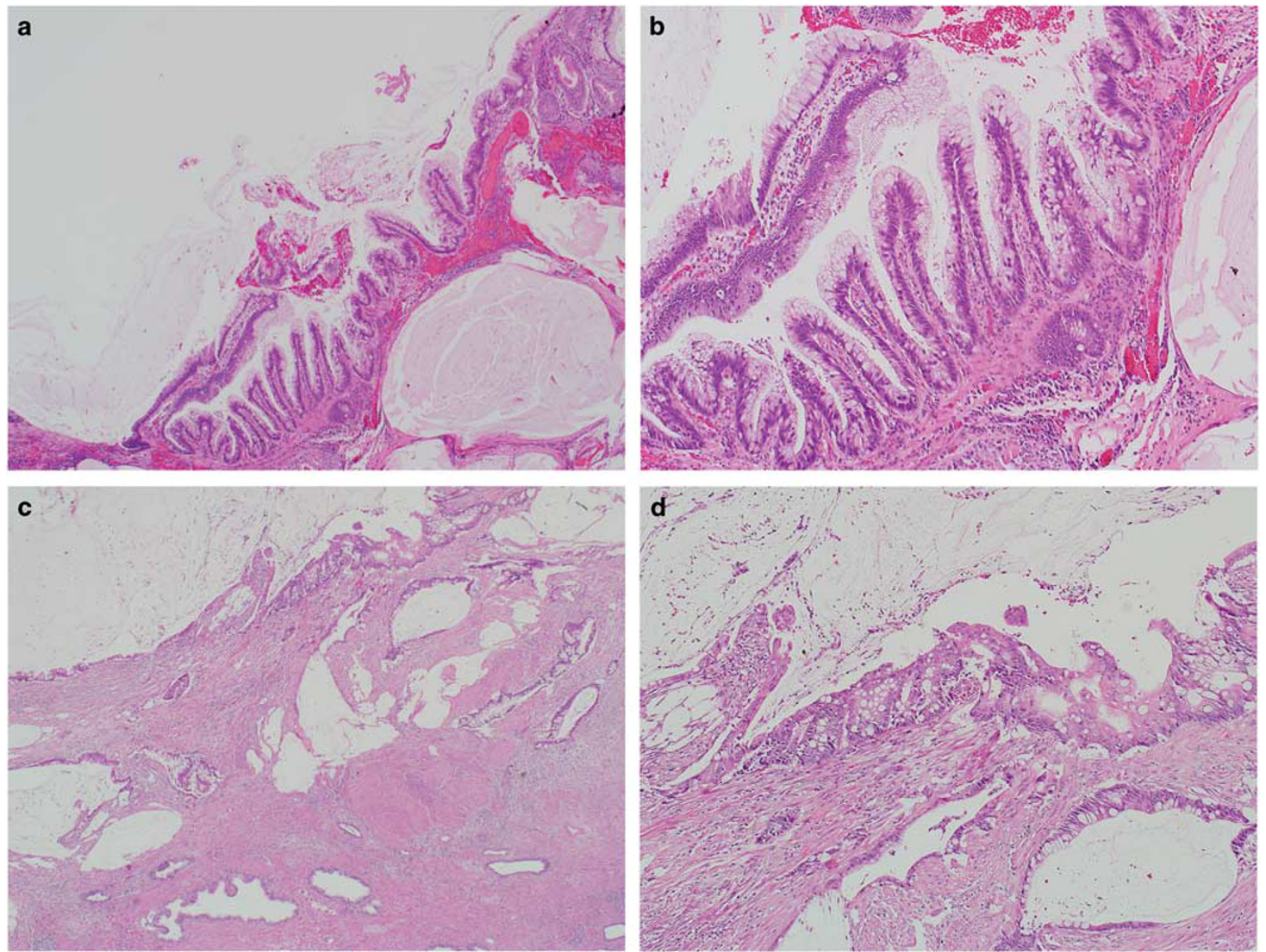

Figure 6 (a) Mucinous adenocarcinoma of the prostatic urethra arising from urethritis glandularis/glandular metaplasia of the prostatic urethra. TURP ( $\times 10$ magnification). (b) Mucinous adenocarcinoma of the prostatic urethra arising from urethritis glandularis/glandular metaplasia of the prostatic urethra. TURP ( $\times 20$ magnification). (c) Mucinous adenocarcinoma of the prostatic urethra arising from urethritis glandularis/glandular metaplasia of the prostatic urethra. Radical cystoprostatectomy $(\times 4$ magnification). (d) Mucinous adenocarcinoma of the prostatic urethra arising from urethritis glandularis/glandular metaplasia of the prostatic urethra. Radical cystoprostatectomy ( $\times 10$ magnification).

prostatic urethra, colonization of prostatic ducts/ acini, invasion of prostatic urethral subepithelial connective tissue, prostatic stromal invasion from the latter and direct transmural invasion through the bladder wall, with variable data on prognostic implications. ${ }^{6,58-62}$ Urothelial carcinoma with prostatic involvement may be detected on prostatic needle core biopsies, TURP, simple prostatectomy, radical prostatectomy, or, more commonly, radical cystoprostatectomy specimens. On prostate needle core biopsies or TURP specimens, it is challenging to determine the site of origin of the tumor especially in the absence of a known history of urothelial carcinoma of the bladder. In addition, in some cases, the prostatic stromal invasion may actually be arising from the prostatic urethra and not the bladder, and thus appropriate tissue sampling is critical in this scenario to ensure appropriate stage designation. The incidence of prostatic involvement by urothelial carcinoma of the urinary bladder in radical cystoprostatectomy specimens ranges from 12 to $48 \%$. 6,7,58,60,63

Urothelial carcinoma of the bladder with prostatic stromal invasion (direct invasion of the prostatic stroma following tumor extension beyond the muscularis propria/Detrusor muscle) is categorized as pT4a in the 2017 American Joint Committee on Cancer/Tumor-Node-Metastasis classification (Figures 12a-c), and urothelial carcinoma of prostatic urethral origin with prostatic stromal involvement is designated as pT2 (Figures 13a and b)., ${ }^{1,7,62-}$ 64 However, urothelial carcinoma in situ of the prostatic urethra or colonization of prostatic ducts and acini without associated stromal invasion does not upstage a tumor to pT2 or pT4a status. ${ }^{1,7,62-64}$

Most experts are in agreement that there is a difference in outcome between patients with urothelial carcinoma in situ of the prostatic urethra or urothelial carcinoma in situ with colonization of prostatic ducts/acini (Figures 14a and b) and patients 

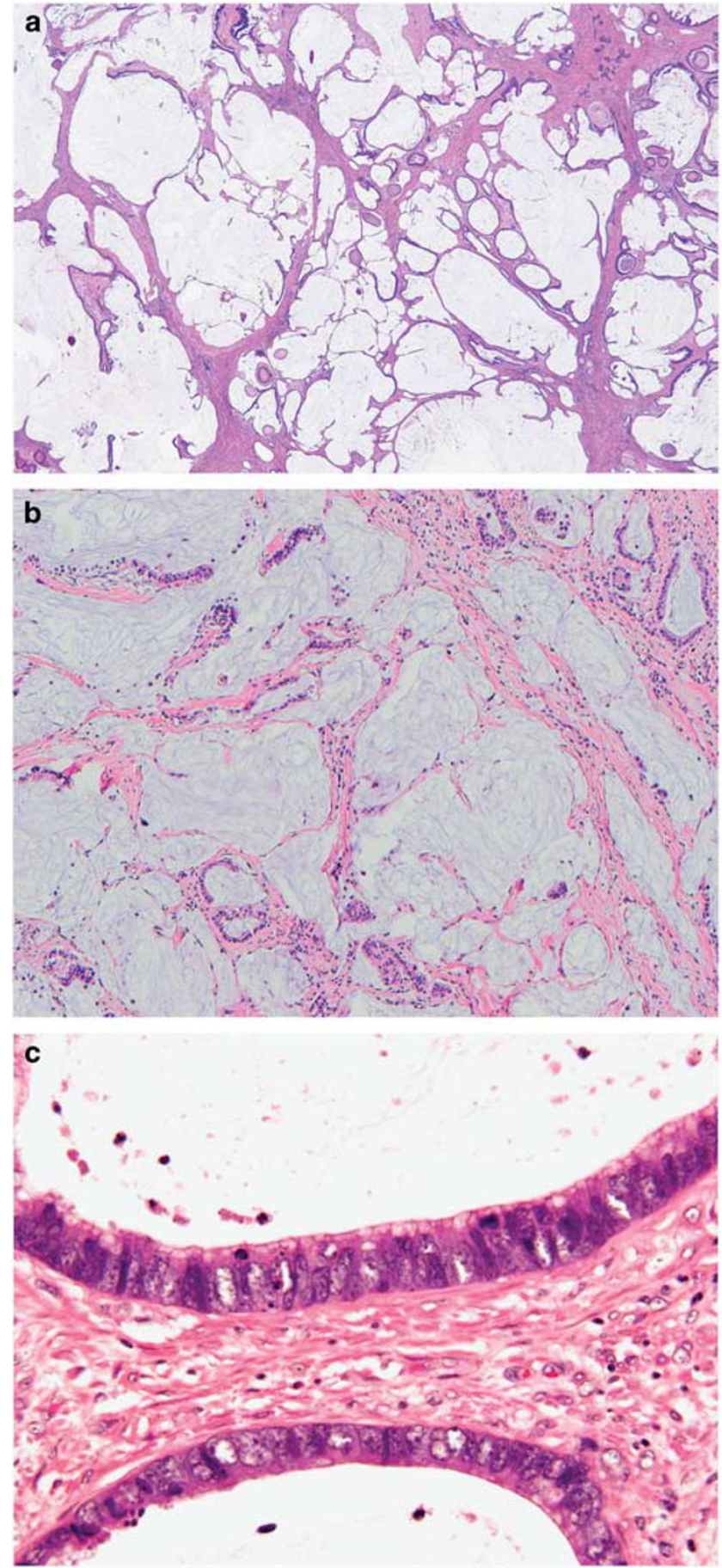

Figure 7 (a) Mucinous adenocarcinoma of the prostatic urethra with dissecting pools of mucin. Radical cystoprostatectomy $(\times 4$ magnification). (b) Mucinous adenocarcinoma of the prostatic urethra with dissecting pools of mucin. Radical cystoprostatectomy (×20 magnification). (c) Mucinous adenocarcinoma of the prostatic urethra with pseudostratified/columnar epithelium. Radical cystoprostatectomy (×60 magnification).

with prostatic stromal invasion. It is thus critical to make the distinction between the two, irrespective of the specimen in which the initial diagnosis was made. The distinction between urothelial carcinoma with prostatic stromal invasion and urothelial
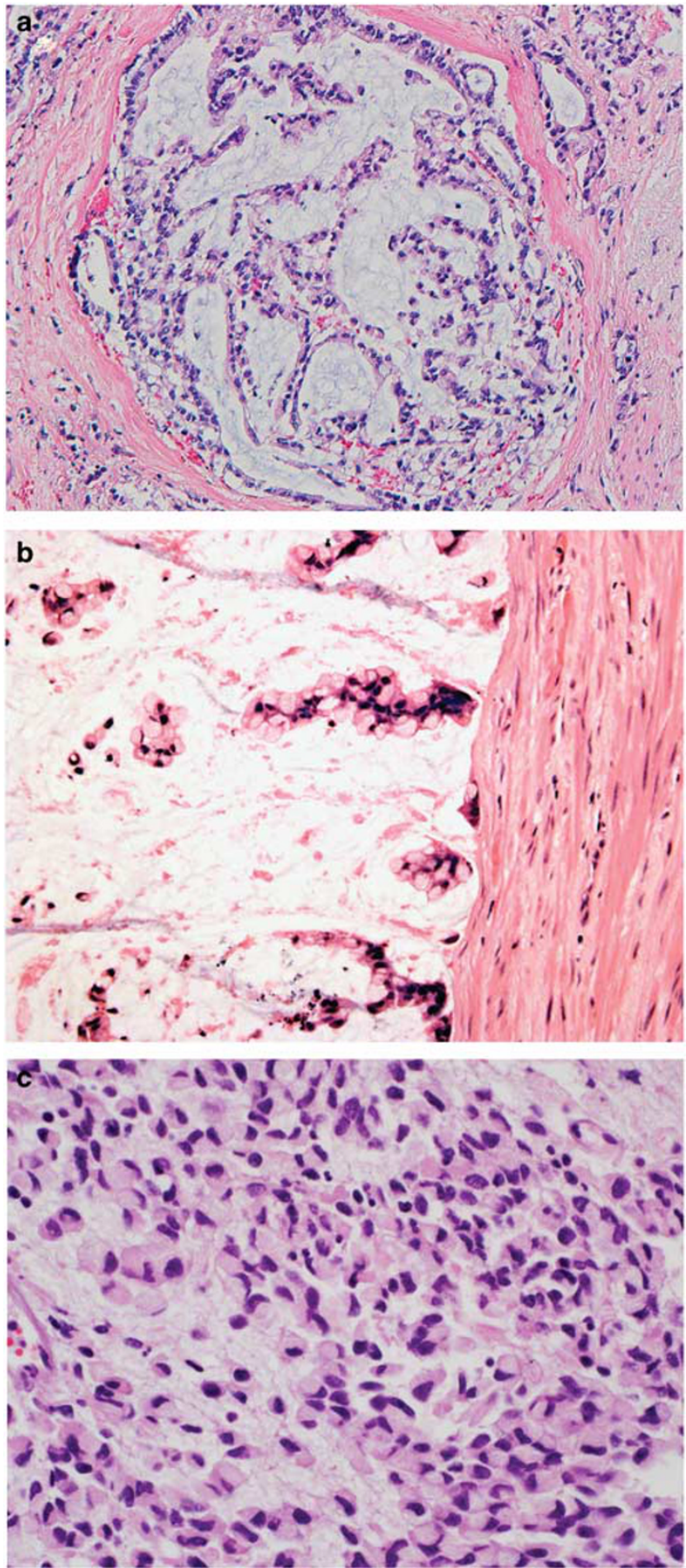

Figure 8 (a) Mucinous adenocarcinoma of the prostatic urethra with cribriform glands, mimicking prostatic adenocarcinoma with mucous features (×20 magnification). (b) Mucinous adenocarcinoma of the prostatic urethra with signet ring cell formation (predominantly mucin pools). Radical cystoprostatectomy $(\times 60$ magnification). (c) Mucinous adenocarcinoma of the prostatic urethra with signet-ring cell formation (predominantly signet ring cells). Radical cystoprostatectomy (×60 magnification).

carcinoma with colonization of prostatic ducts and acini can be somewhat challenging in some cases on H\&E (especially in needle core biopsies or TURP 


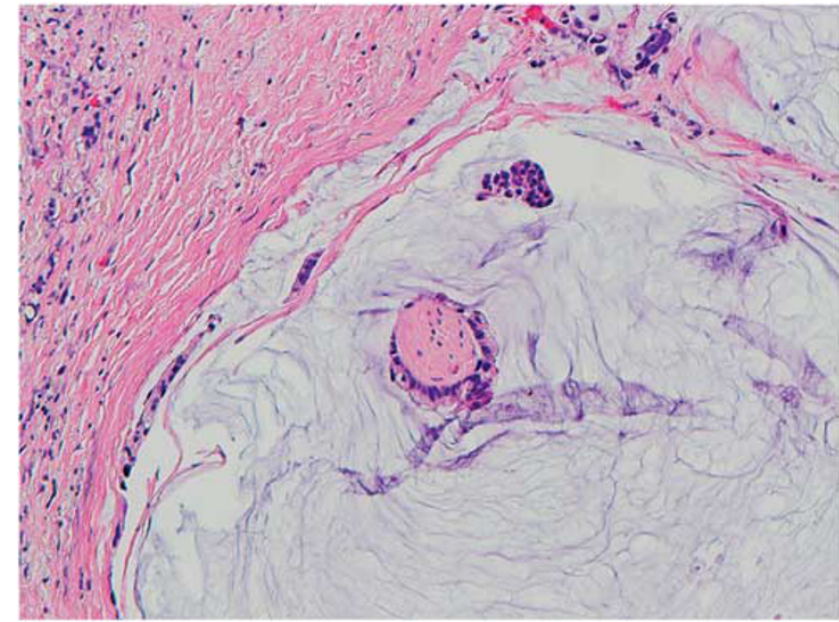

Figure 9 Mucinous adenocarcinoma of the prostatic urethra with extensive pools of mucin and focus of perineural invasion. Radical cystoprostatectomy ( $\times 20$ magnification).
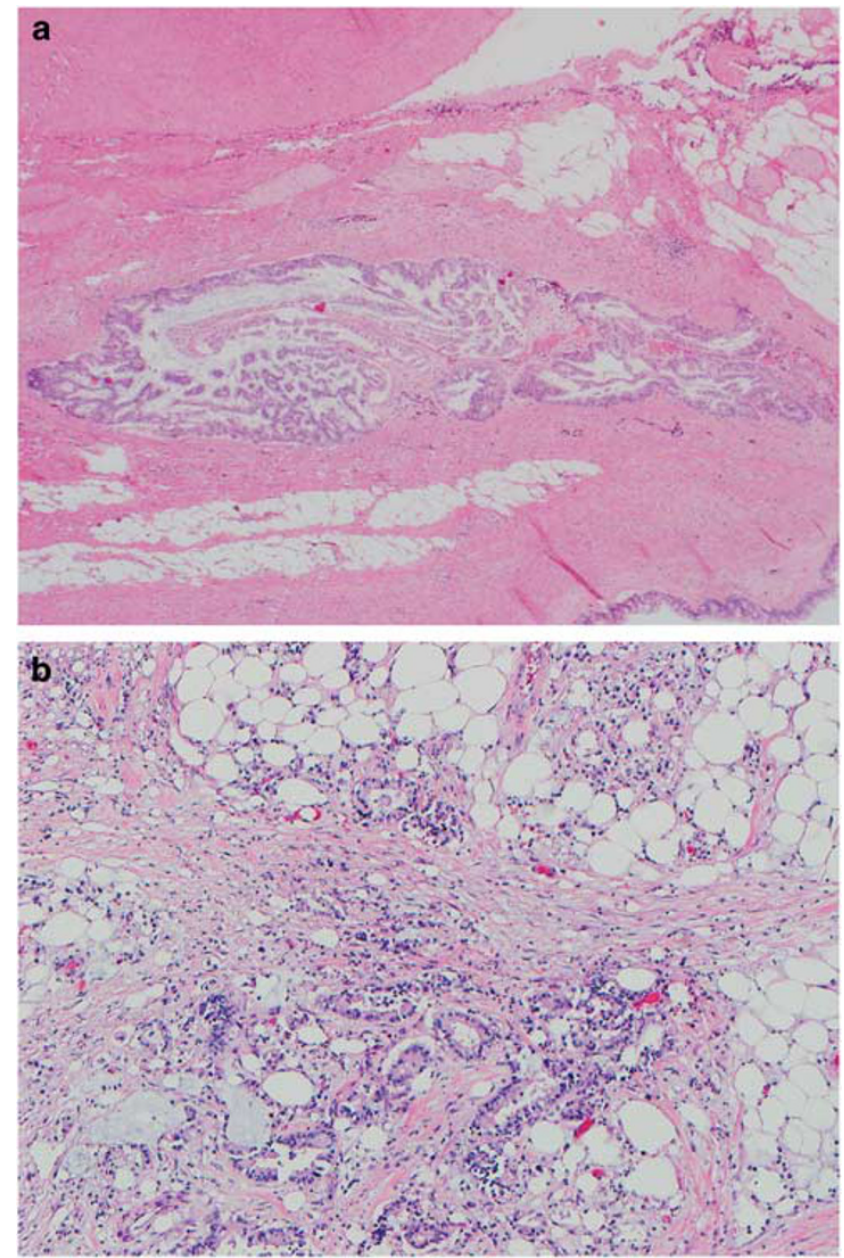

Figure 10 (a) Mucinous adenocarcinoma of the prostatic urethra with extraprostatic extension. Radical cystoprostatectomy $(\times 10$ magnification). (b) Mucinous adenocarcinoma of the prostatic urethra with extraprostatic extension. Radical cystoprostatectomy ( $\times 20$ magnification). specimens), and is one of the relatively common urological pathology consultation cases sent to experts. Pathologists rely on somewhat subjective methods/criteria to aid in the determination of prostatic stromal invasion such as stromal desmoplastic response, host inflammatory response, and irregular urothelial nests. Urothelial carcinoma in situ with colonization of prostatic ducts and acini may be associated with a periductal/periacinar stromal response, including desmoplasia and inflammation in an analogous manner to what is seen with ductal carcinoma in situ of the breast, especially in extensive cases. In addition to irregular nests, other features helpful to make a definitive diagnosis of invasion in this setting are either nests of tumor cells with retraction artifact or single tumor cells. Previous studies have demonstrated that readily available immunohistochemical stains such as p63 and HMWCK may be helpful in the distinction between urothelial carcinoma with prostatic stromal invasion and urothelial carcinoma with colonization of prostatic ducts and acini. ${ }^{64}$ Other authors have also utilized CK5, CK5/6, and double-stains CK7/CK5 and p53/CK5, in this setting. ${ }^{65}$ However, it is important to note that in some cases it may be difficult to distinguish tumor cells from the basal cells even with these immunohistochemical stains.

Although there are a number of entities that should be distinguished from urothelial carcinoma of the bladder involving the prostate (including prostate cancer, discussed below), the most important benign entities are urothelial metaplasia and basal cell hyperplasia. These two different entities do not usually cause diagnostic challenges, however in cases of florid urothelial metaplasia or florid basal cell hyperplasia, unsuspecting pathologists may misinterpret them as a malignant process such as urothelial carcinoma. ${ }^{11}$ One of the key diagnostic features of these two benign entities is the preservation of a lobular architecture. In addition, unlike urothelial carcinoma with prostatic stromal invasion, a desmoplastic stromal response and/or retraction artifact are usually absent.

Making the distinction between invasive high grade urothelial carcinoma of the bladder with prostatic stromal invasion and prostatic adenocarcinoma is critical, in view of the different therapeutic options for these tumors. In cases that are challenging on $\mathrm{H} \& \mathrm{E}$, readily available immunohistochemical stains (PSA, PSAP, GATA3, p63, HMWCK, thrombomodulin, and uroplakin) can aid in the distinction between these two entities in most cases. In the few cases in which the distinction still cannot be made with the previous markers, additional immunohistochemical stains such as NKX3.1, P501S, PSMA, and pPSA that are typically positive even in advanced prostatic adenocarcinoma, and negative in urothelial carcinoma may be useful. ${ }^{11,25,66-68}$ 

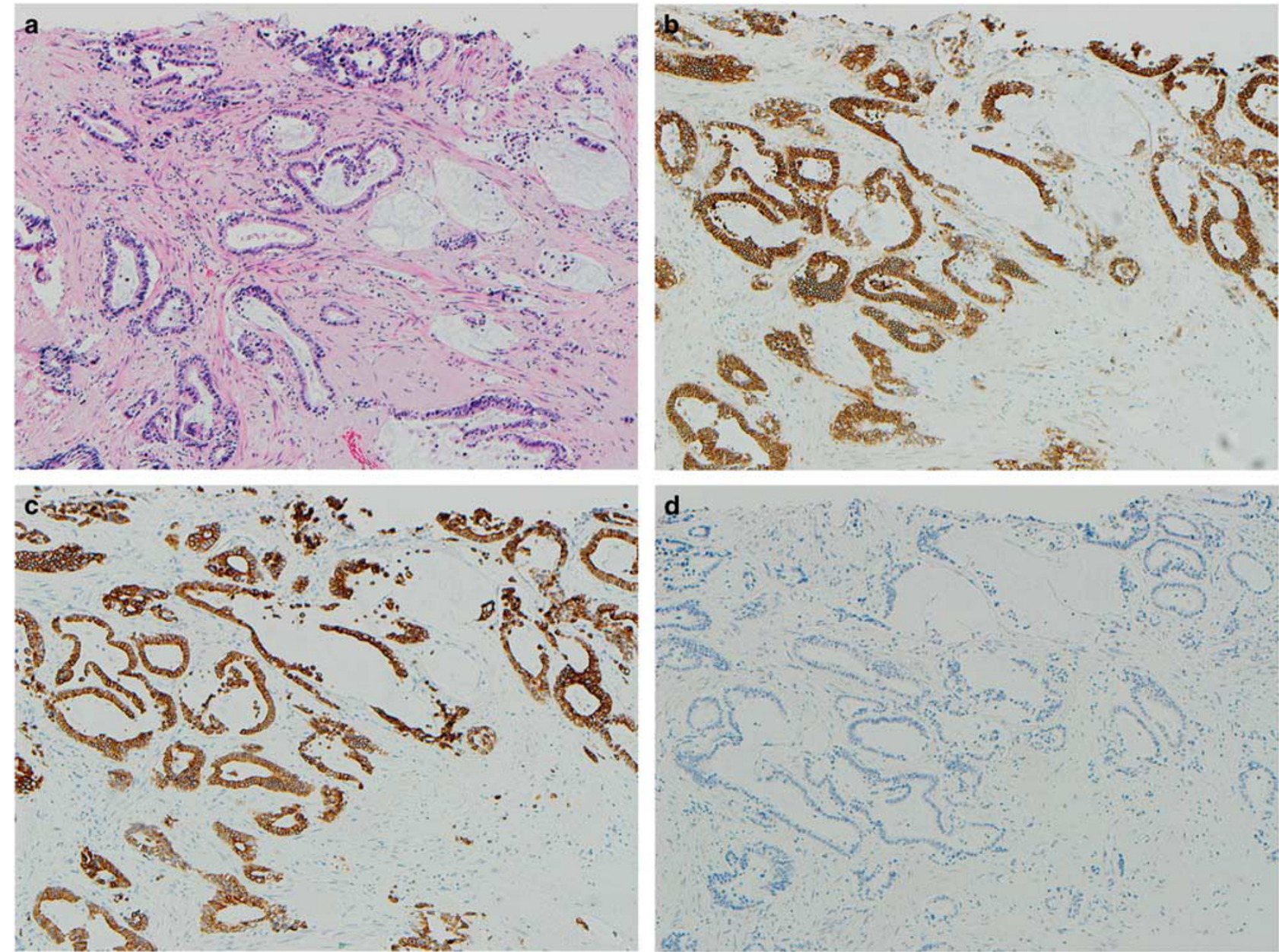

Figure 11 (a) Mucinous adenocarcinoma of the prostatic urethra. (b) Mucinous adenocarcinoma of the prostatic urethra with positive CK7 expression (focus corresponds to a). (c) Mucinous adenocarcinoma of the prostatic urethra with positive HMWCK expression (focus corresponds to a). (d) Mucinous adenocarcinoma of the prostatic urethra with negative NKX3.1 expression (focus corresponds to a).

In summary, it is important to note that urothelial carcinoma involving the prostate, may actually be originating from the prostatic urethra, although in several cases the bladder is the site of origin. It is also critical to distinguish invasive high-grade urothelial carcinoma of the bladder with prostatic stromal invasion from prostatic adenocarcinoma and benign mimics.

\section{Colorectal adenocarcinoma with involvement of the prostate}

Despite the proximity of the colorectum to the prostate, involvement of the prostate from this site in clinical specimens is relatively rare (Figures 15ac), with only few case series and case reports in the literature. ${ }^{9,11,46,47,69,70}$ Although most patients present with classic symptoms of colorectal carcinoma, patients may present with obstructive uropathy due to involvement of the prostatic urethra, and therefore may be diagnosed for the first time following TURP. ${ }^{9}$
Secondary involvement of the prostate from the colorectum can occur either by direct extension or by discrete metastases as evidenced by colon cancer involving the prostate in cases with initial pT1 colon cancer. The paucity of cases of colorectal carcinoma directly invading the prostate is due to several factors. Denonvillier fascia, the compressed prostatic capsule, plays a key role in impeding the extension of surrounding tumors into the prostate gland. ${ }^{9}$

In one of the largest case series to date, a couple of patients had prostatic extension of colorectal adenocarcinoma followed reanastomosis of a resected segment of colon. ${ }^{9}$ In these cases, it is likely that there was disruption of the Denonvillier fascia, which made the localized spread of the recurrent colonic cancer to the prostate gland easier. Welldocumented cases of discrete metastases are uncommon. There has been a reported case of metastasis of an ascending colon carcinoma to the prostate 10 years after hemicolectomy (one of the longest intervals in the literature) in an 80-year-old man. ${ }^{46}$ The patient had a history of partial resection of the 

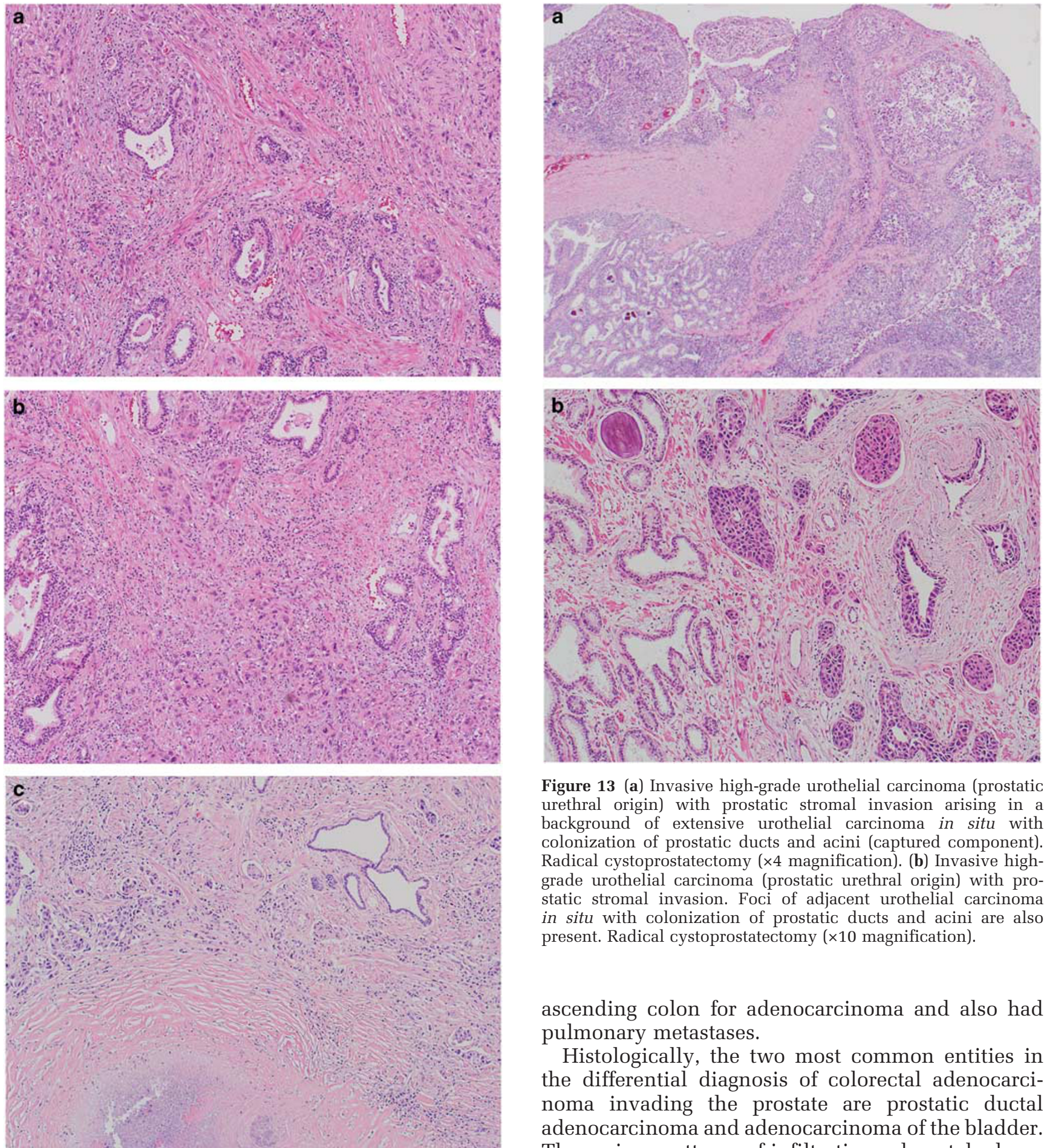

Figure 13 (a) Invasive high-grade urothelial carcinoma (prostatic urethral origin) with prostatic stromal invasion arising in a background of extensive urothelial carcinoma in situ with colonization of prostatic ducts and acini (captured component). Radical cystoprostatectomy ( $\times 4$ magnification). (b) Invasive highgrade urothelial carcinoma (prostatic urethral origin) with prostatic stromal invasion. Foci of adjacent urothelial carcinoma in situ with colonization of prostatic ducts and acini are also present. Radical cystoprostatectomy (×10 magnification).

ascending colon for adenocarcinoma and also had pulmonary metastases.

Histologically, the two most common entities in the differential diagnosis of colorectal adenocarcinoma invading the prostate are prostatic ductal adenocarcinoma and adenocarcinoma of the bladder. The various patterns of infiltrating colorectal adeno-

Figure 12 (a) Invasive high-grade urothelial carcinoma (bladder origin) with prostatic stromal invasion. Note desmoplastic stromal reaction and inflammation radical cystoprostatectomy $(\times 10$ magnification). (b) Invasive high-grade urothelial carcinoma (bladder origin) with prostatic stromal invasion. Note desmoplastic stromal reaction and inflammation radical cystoprostatectomy $(\times 10$ magnification). (c) Invasive high-grade urothelial carcinoma (bladder origin) with prostatic stromal invasion. Note adjacent necrotizing granulomatous inflammation from prior BCG therapy. Radical cystoprostatectomy ( $\times 10$ magnification). carcinoma, including mucinous, enteric, and signetring cell type may also be seen in variants of prostatic adenocarcinoma. However, true mucinpositive signet-ring cells are exceedingly rare in prostatic adenocarcinoma. In addition, prostatic ductal adenocarcinoma with rare exception lacks mucinous epithelium, intraluminal or extracellular mucin, and prostatic ductal adenocarcinoma is often admixed with conventional prostatic adenocarcinoma that has distinctive morphology. 

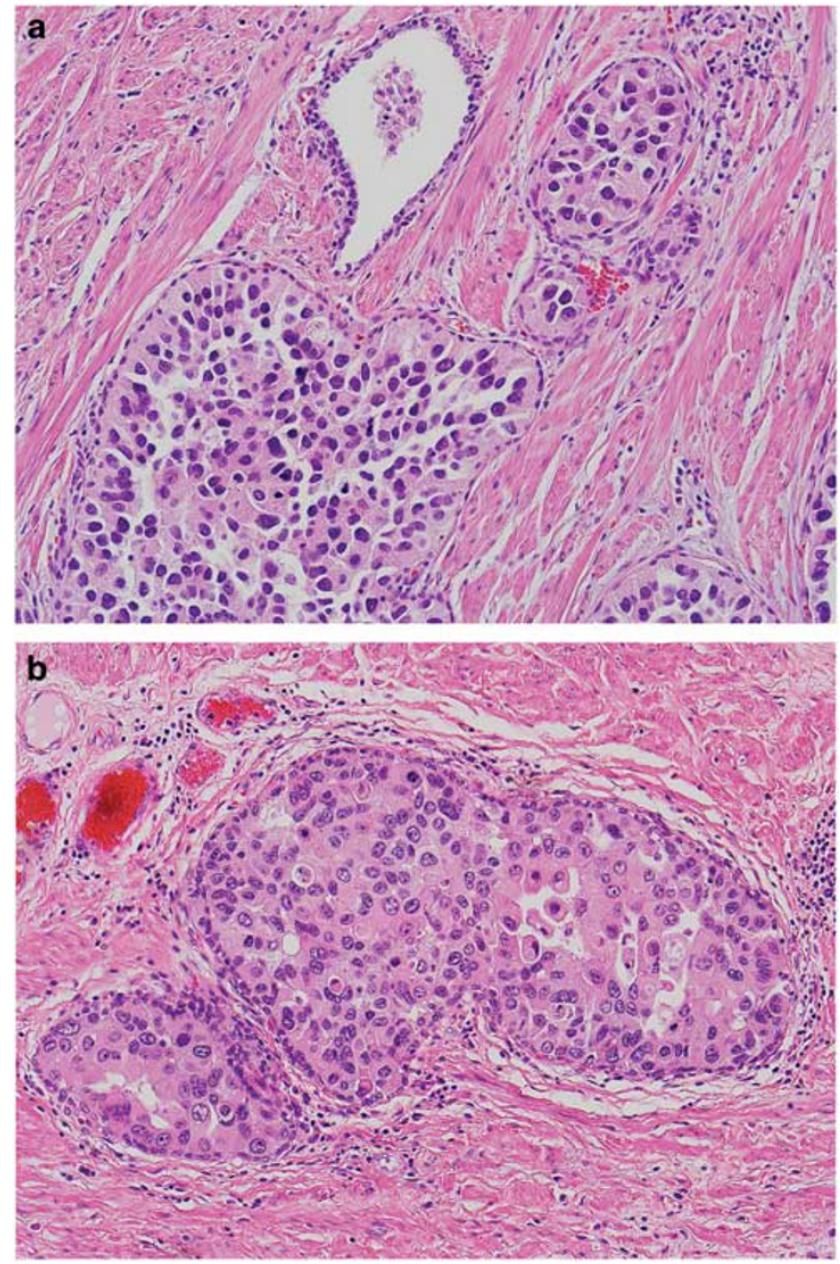

Figure 14 (a) Urothelial carcinoma in situ with colonization of prostatic ducts/acini ( $\times 20$ magnification). (b) Urothelial carcinoma in situ with colonization of prostatic ducts/acini $(\times 20$ magnification).

In challenging cases, especially in biopsy specimens, immunohistochemical stains can be helpful. Most colonic adenocarcinomas are positive for CDX2, villin, b-catenin (nuclear stain), mucins (MUC1 and MUC3), CEA, and B72.3, and all are negative for prostate-specific markers (PSA, PSAP, p504s, NKX3.1, etc). ${ }^{25,43,70}$ In addition, it is important to note that distorted benign colorectal epithelium may be intimately associated with prostatic tissue and may mimic prostatic adenocarcinoma on needle core biopsies. ${ }^{71}$

\section{Gastrointestinal stromal tumor}

A challenging and well-described scenario (especially on needle core biopsy) is one in which a patient has a positive DRE and on imaging appears to have a mass involving the prostate or extending in between the prostate and the colorectum. One of the entities to consider in this setting is a gastrointestinal stromal tumor (GIST). Most cases of 'prostatic' GIST
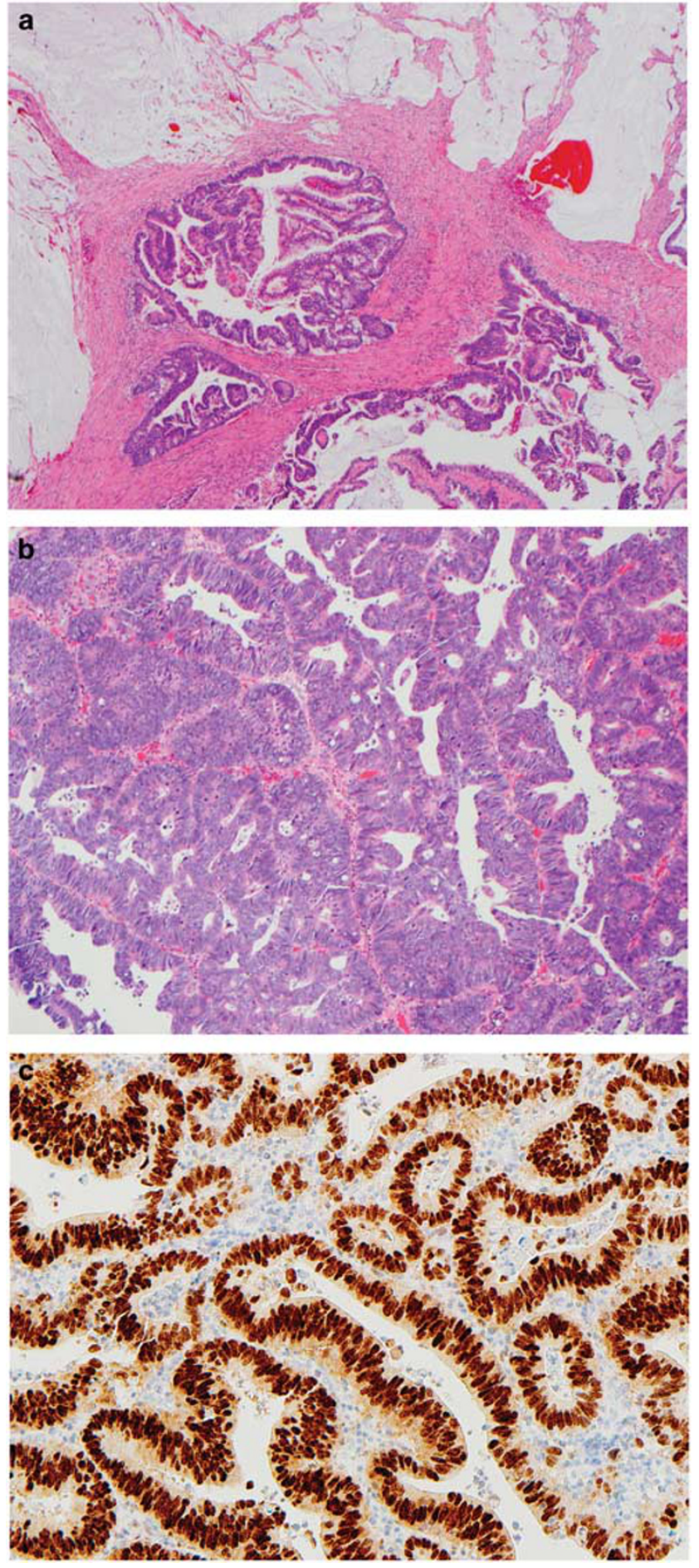

Figure 15 (a) Colorectal adenocarcinoma with mucinous features involving the prostate (pelvic exenteration $\times 10$ magnification). (b) Colorectal adenocarcinoma involving the prostate (TURP $\times 20$ magnification). (c) Colorectal adenocarcinoma involving the prostate with positive CDX2 expression (focus corresponds to b).

are sampled on needle core biopsy, and one of the clues to the diagnosis is the absence of prostatic glands and stroma in the cores that are involved. This is due to the fact that the vast majority of these tumors arise from the colorectal wall, and are not 

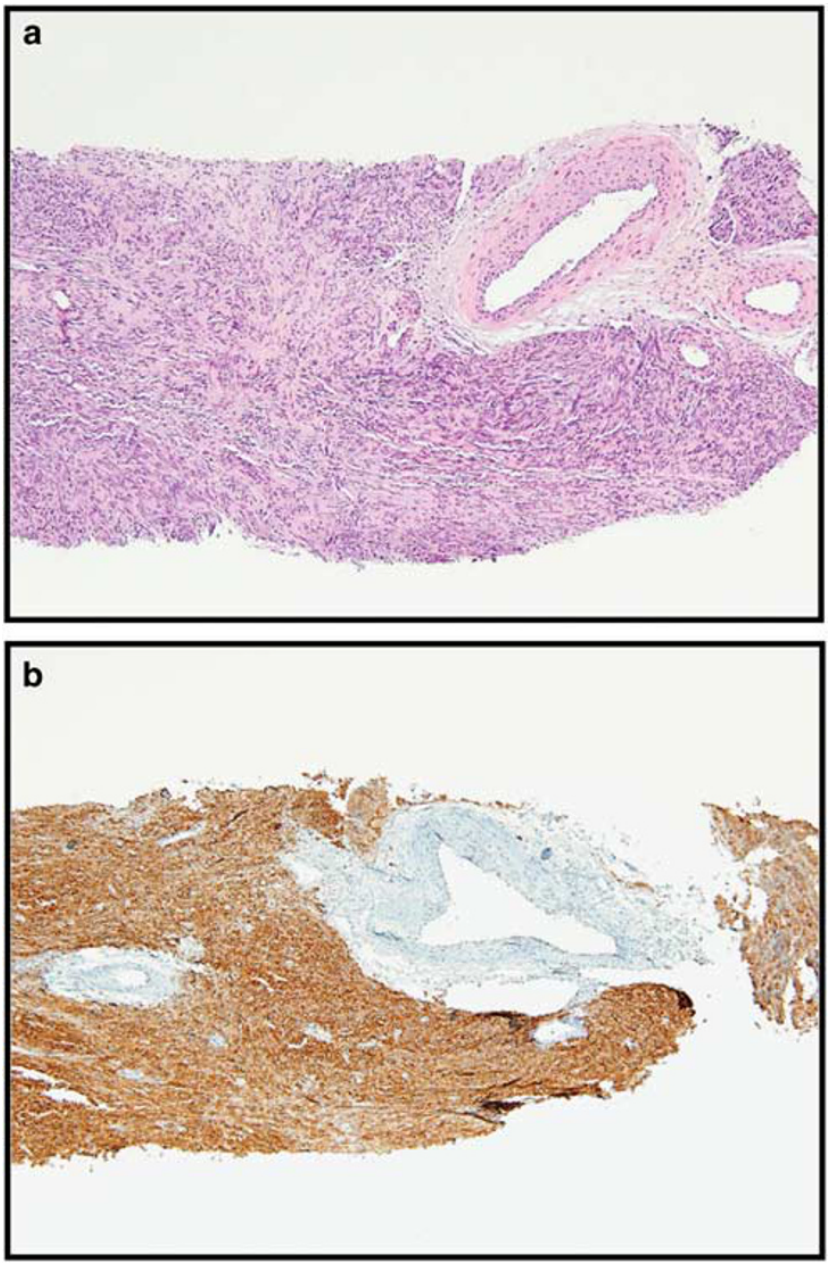

Figure 16 (a) Gastrointestinal stromal tumor diagnosed on 'prostate' needle core biopsy. (b) Gastrointestinal stromal tumor with positive CD117 expression (focus corresponds to a).

true GIST of prostatic origin. ${ }^{72-77}$ Unfortunately, if GIST is misdiagnosed as a sarcoma, patients may undergo unnecessary pelvic exenteration or chemoradiation therapy. GISTs in this location are similar to those at other sites, thus the tumors are typically positive for CD117, CD34, and DOG1 (Figures 16a and $b)$.

\section{Metastatic malignant teratoma to the prostate}

Testicular germ cell tumors are the most common solid malignancy of young men aged 15-40 years, representing $\sim 1 \%$ of all malignancies in men. ${ }^{1}$ The majority of stage I non-seminomatous germ cell tumors (NSGCTs) are treated with radical orchiectomy followed by surveillance, a platinum-based chemotherapy, retroperitoneal lymph-node dissection, or a combination of the above therapies. Stage I patients are divided into low risk (20\% relapse rate) or high risk (40-50\% relapse rate) depending on the
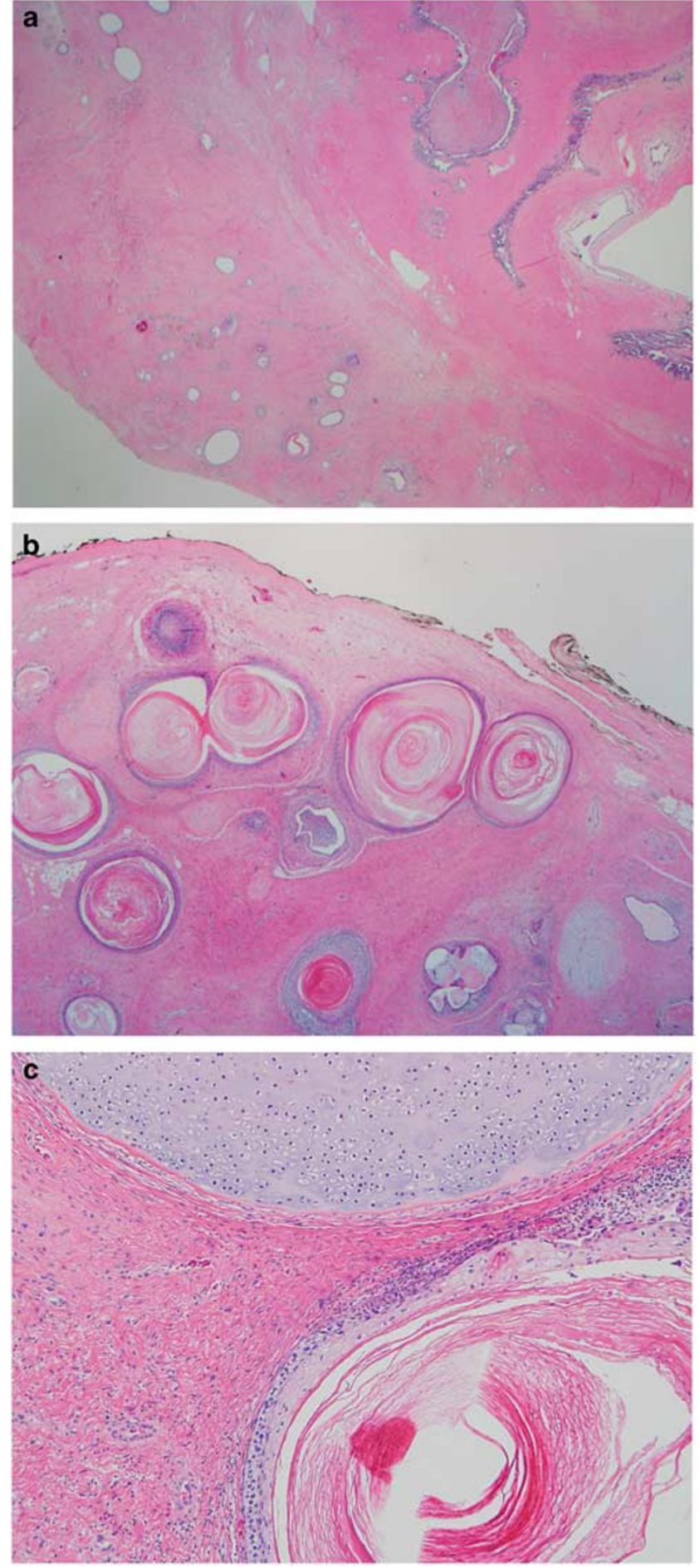

Figure 17 (a) Metastatic malignant teratoma involving the prostate and seminal vesicle ( $\times 2$ magnification). (b) Metastatic malignant teratoma involving the prostate and periprostatic tissue $(\times 4$ magnification). (c) Metastatic malignant teratoma involving the prostate $(\times 20$ magnification).

presence of vascular or lymphatic invasion. Low-risk stage I NSGCT patients are can be offered treatment with a radical orchiectomy followed by surveillance with excellent rates of cancer-specific survival. In 
NSGCTs, $89 \%$ of relapses occur within the first 2 years after treatment. The most common sites of recurrence are the retroperitoneal lymph nodes and the lungs, but other sites of recurrence may also occur, including the liver, brain, bone, kidney, adrenal gland, and the gastrointestinal tract. Recurrences of metastatic primary testicular cancer to the prostate are extremely rare, with very few case reports of metastatic germ cell tumors to the prostate. ${ }^{78-85}$ In these previous reports, patients with prostatic metastases have presented for evaluation following the onset of obstructive voiding symptoms or with abdominal/back pain. Prostatic metastases were identified at the time of initial diagnosis for one patient's primary testicular seminoma, but they have also occurred as late as 16 years after the primary diagnosis. ${ }^{83}$ In these patients, pathologic diagnosis was confirmed by transurethral resection, prostate biopsy, or urine cytology. These patients were also initially managed with either platinum-based chemotherapy and/or radiation therapy. One patient ultimately required a cystoprostatectomy for CTconfirmed residual disease in the prostate. Although the vast majority of these cases have reported prostatic recurrences from primary testicular seminomas, very rarely metastatic malignant teratoma may involve the prostate (Figures $17 \mathrm{a}-\mathrm{c}$ ). ${ }^{84,85}$ The main differential diagnosis to consider includes spread (direct extension or metastasis) of tumors from other sites to the prostate. In summary, metastatic malignant teratoma (or germ cell tumors in general) to the prostate though relatively uncommon may occur, and this case emphasizes the fact that one should always keep an open mind when unusual morphologic features are present in the prostate.

In summary, mucinous and secondary tumors of the prostate are relatively uncommon in contrast to conventional prostatic adenocarcinoma, and it is critical for pathologists (and our clinical colleagues) to be aware of the potential diagnostic pitfalls and therapeutic/prognostic implications associated with these entities.

\section{Disclosure/conflict of interest}

The author declares no conflict of interest.

\section{References}

1 Moch H, Humphrey PA, Ulbright TM, et al. (eds). WHO Classification of Tumors of the Urinary System and Male Genital Organs, 4th edn. IARC: Lyon, France, 2016.

2 Bohman KD, Osunkoya AO. Mucin-producing tumors and tumor-like lesions involving the prostate: a comprehensive review. Adv Anat Pathol 2012;19: 374-387.

3 Osunkoya AO, Nielsen ME, Epstein JI. Prognosis of mucinous adenocarcinoma of the prostate treated by radical prostatectomy: a study of 47 cases. Am J Surg Pathol 2008;32:468-472.

4 Osunkoya AO, Epstein JI. Primary mucin-producing urothelial-type adenocarcinoma of prostate: report of 15 cases. Am J Surg Pathol 2007;31:1323-1329.

5 Bates AW, Baithun SI. Secondary solid neoplasms of the prostate: a clinico-pathological series of 51 cases. Virchows Arch 2002;440:392-396.

6 Revelo MP, Cookson MS, Chang SS, et al. Incidence and location of prostate and urothelial carcinoma in prostates from cystoprostatectomies: implications for possible apical sparing surgery. J Urol 2004;171: 646-651.

7 Oliva IV, Smith SL, Chen Z, et al. Urothelial carcinoma of the bladder with transmural and direct prostatic stromal invasion: does extent of stromal invasion significantly impact patient outcome? Hum Pathol 2011;42:51-56.

8 Mai KT, Landry DC, Collins JP. Secondary colonic adenocarcinoma of the prostate histologically mimicking prostatic ductal adenocarcinoma. Tumori 2002;88: 341-344.

9 Osunkoya AO, Netto GJ, Epstein JI. Colorectal adenocarcinoma involving the prostate: report of 9 cases. Hum Pathol 2007;38:1836-1841.

10 Marcus DM, Goodman M, Jani AB, et al. A comprehensive review of incidence and survival in patients with rare histological variants of prostate cancer in the United States from 1973 to 2008. Prostate Cancer Prostatic Dis 2012;15:283-288.

11 Osunkoya AO. Update on prostate pathology. Pathology 2012;44:391-406.

12 Lane BR, Magi-Galluzzi C, Reuther AM, et al. Mucinous adenocarcinoma of the prostate does not confer poor prognosis. Urology 2006;68:825-830.

13 Epstein JI, Egevad L, Amin MB, et al. The 2014 International Society of Urological Pathology (ISUP) Consensus Conference on Gleason Grading of Prostatic Carcinoma: definition of grading patterns and proposal for a new grading system. Am J Surg Pathol 2016;40: 244-252.

14 Epstein JI, Lieberman PH. Mucinous adenocarcinoma of the prostate gland. Am J Surg Pathol 1985;9:299-308.

15 Franks LM, O'shea JD, Thomson AE. Mucin in the prostate: a histochemical study in normal glands, latent, clinical, and colloid cancers. cancer 1964;17: 983-991.

16 Ro JY, Grignon DJ, Ayala AG, et al. Mucinous adenocarcinoma of the prostate: histochemical and immunohistochemical studies. Hum Pathol 1990;21: 593-600.

17 Osunkoya AO, Adsay NV, Cohen C, et al. MUC2 expression in primary mucinous and nonmucinous adenocarcinoma of the prostate: an analysis of 50 cases on radical prostatectomy. Mod Pathol 2008;21:789-794.

18 Adsay NV, Merati K, Nassar H, et al. Pathogenesis of colloid (pure mucinous) carcinoma of exocrine organs: coupling of gel-forming mucin (MUC2) production with altered cell polarity and abnormal cell-stroma interaction may be the key factor in the morphogenesis and indolent behavior of colloid carcinoma in the breast and pancreas. Am J Surg Pathol 2003;27: $571-578$

19 Lotan TL, Carvalho FL, Peskoe SB, et al. PTEN loss is associated with upgrading of prostate cancer from biopsy to radical prostatectomy. Mod Pathol 2015;28: 128-137. 
20 Lotan TL, Gumuskaya B, Rahimi H, et al. Cytoplasmic PTEN protein loss distinguishes intraductal carcinoma of the prostate from high-grade prostatic intraepithelial neoplasia. Mod Pathol 2013;26:587-603.

21 Lotan TL, Gurel B, Sutcliffe S, et al. PTEN protein loss by immunostaining: analytic validation and prognostic indicator for a high risk surgical cohort of prostate cancer patients. Clin Cancer Res 2011;17:6563-6573.

22 Gurel B, Iwata T, Koh CM, et al. Molecular alterations in prostate cancer as diagnostic, prognostic, and therapeutic targets. Adv Anat Pathol 2008;15: 319-331.

23 McMenamin ME, Soung P, Perera S, et al. Loss of PTEN expression in paraffin-embedded primary prostate cancer correlates with high Gleason score and advanced stage. Cancer Res 1999;59:4291-4296.

24 Bertsch EC, Magi-Galluzzi C, Cheng L, et al. PTEN expression in mucinous prostatic adenocarcinoma, prostatic adenocarcinoma with mucinous features and adjacent conventional prostatic adenocarcinoma: a multi-institutional study of 92 cases. Appl Immunohistochem Mol Morphol 2016, [PMID:27438514].

25 Epstein JI, Egevad L, Humphrey PA, et al. Best practices recommendations in the application of immunohistochemistry in the prostate: report from the International Society of Urologic Pathology consensus conference. Am J Surg Pathol 2014;38:e6-e19.

26 Johnson H, Zhou M, Osunkoya AO. ERG expression in mucinous prostatic adenocarcinoma and prostatic adenocarcinoma with mucinous features: comparison with conventional prostatic adenocarcinoma. Hum Pathol 2013;44:2241-2246.

27 Leite KR, Mitteldorf CA, Srougi M, et al. Cdx2, cytokeratin 20, thyroid transcription factor 1 , and prostate-specific antigen expression in unusual subtypes of prostate cancer. Ann Diagn Pathol 2008;12: 260-266.

28 Han B, Mehra R, Suleman K, et al. Characterization of ETS gene aberrations in select histologic variants of prostate carcinoma. Mod Pathol 2009;22:1176-1185.

29 Beach R, Gown AM, De Peralta-Venturina MN, et al. P504S immunohistochemical detection in 405 prostatic specimens including 376 18-gauge needle biopsies. Am J Surg Pathol 2002;26:1588-1596.

30 Loo KT, Chan JK. Colloid adenocarcinoma of the urethra associated with mucosal in situ carcinoma. Arch Pathol Lab Med 1992;116:976-977.

31 Curtis MW, Evans AJ, Srigley JR. Mucin-producing urothelial-type adenocarcinoma of prostate: report of two cases of a rare and diagnostically challenging entity. Mod Pathol 2005;18:585-590.

32 Osunkoya AO, Epstein JI. Primary mucin-producing urothelial-type adenocarcinoma of prostate: report of 15 cases. Am J Surg Pathol 2007;31:1323-1329.

33 Sakamoto N, Ohtsubo S, Iguchi A, et al. Intestinal-type mucinous adenocarcinoma arising from the prostatic duct. Int J Urol 2005;12:509-512.

34 Silverman ML, Eyre RC, Zinman LA, et al. Mixed mucinous and papillary adenocarcinoma involving male urethra, probably originating in periurethral glands. Cancer 1981;47:1398-1402.

35 Harari SE, Cheng L, Osunkoya AO. Primary mucinous adenocarcinoma of the female urethra: a contemporary clinicopathologic analysis. Hum Pathol 2016;47: 132-137.

36 Abeshouse B. Primary and secondary melanoma of the genitourinary tract. South Med J 1958;51:994-1006.
37 Johnson DE, Chalbaud R, Ayala AG. Secondary tumors of the prostate. J Urol 1974;112:507-508.

38 Cihak RW, Haas R, Koenen CT, et al. Metastatic renal carcinoma to the prostate gland: presentation as prostatic hypertrophy. J Urol 1980;123:791-792.

39 Smedley HM, Brown C, Turner A. Ectopic ACTHproducing lung cancer presenting with prostatic metastasis. Postgrad Med J 1983;59:371-372.

40 Zein TA, Huben R, Lane W, et al. Secondary tumors of the prostate. J Urol 1985;133:615-616.

41 Watson CJ, Doyle PT. Gastric carcinoma presenting as urinary retention. Br J Urol 1990;66:431.

42 Bamberger $\mathrm{MH}$, Romas NA. Clinically significant metastatic melanoma to prostate. Urology 1990;35: 445-447.

43 Berman JR, Nunnemann RG, Broshears JR, et al. Sigmoid colon carcinoma metastatic to prostate. Urology 1993;41:150-152.

44 Madersbacher S, Schatzl G, Susani M, et al. Prostatic metastasis of a small cell lung cancer in a young male. Eur Urol 1994;26:267-269.

45 King DH, Centeno AS, Saldivar VA, et al. Renal cell carcinoma metastatic to the gallbladder or prostate: two case reports. Urology 1995;46:722-725.

46 Schips L, Zigeuner RE, Langner C, et al. Metastasis of an ascending colon carcinoma in the prostate 10 years after hemicolectomy. J Urol 2002;168:641-642.

47 Gupta T, Laskar SG, Thakur M, et al. Isolated prostatic metastasis from primary sigmoid colon carcinoma. Indian J Gastroenterol 2004;23:114-115.

48 Cobo Dols M, Muñoz Gallardo S, Peláez Angulo J, et al. Secondary signet-ring cell tumour of the prostate derived from a primary gastric malignancy. Clin Transl Oncol 2005;7:409-412.

49 Greene GF, Gokden N, Hutchins LF, et al. Metastatic renal cell carcinoma to prostate. Urology 2005;65: 1227.e23-1227.e25.

50 Rodriguez A, Kang L, Politis C, et al. Delayed metastatic renal carcinoma to prostate. Urology 2006; 67:623.e7-623.e10.

51 Fokt RM, Templeton A, Gillessen S, et al. Prostatic metastasis of renal cell carcinoma successfully treated with sunitinib. Urol Int 2009;83:122-124.

52 Yoo JH, Lee JH, Kim EK, et al. Prostatic metastasis of large cell neuroendocrine carcinoma of the lung. Respirology 2009;14:772-775.

53 Zhang $\mathrm{P}$, Zheng $\mathrm{Y}$, Ran $\mathrm{H}$, et al. Case report: gastric adenocarcinoma metastatic to the prostate gland. J Radiol Case Rep 2010;4:35-38.

54 Barba Abad J, Robles García JE, Tolosa Eizaguirre E, et al. Lung cancer metastasizing to the prostate: case report and literature review. Actas Urol Esp 2010;34: 918-920.

55 Youssef FR, Hunt L, Meiring PD, et al. Metastasis of a cecal adenocarcinoma to the prostate five years after a right hemicolectomy: a case report. J Med Case Rep 2011;5:223.

56 Roshni S, Anoop T, Preethi T, et al. Gastric adenocarcinoma with prostatic metastasis. J. Gastric Cancer 2014;14:135-137.

57 Fusco N, Sciarra A, Guerini-Rocco E, et al. Rediscovering secondary tumors of the prostate in the molecular era. Adv Anat Pathol 2016;23:170-179.

58 Schellhammer PF, Bean MA, Whitmore WF Jr. Prostatic involvement by transitional cell carcinoma: pathogenesis, patterns and prognosis. J Urol 1977;118: 399-403. 
59 Esrig D, Freeman JA, Elmajian DA, et al. Transitional cell carcinoma involving the prostate with a proposed staging classification for stromal invasion. J Urol 1996;156:1071-1076.

60 Shen SS, Lerner SP, Muezzinoglu B, et al. Prostatic involvement by transitional cell carcinoma in patients with bladder cancer and its prognostic significance. Human Pathol 2006;37:726-734.

61 Lerner SP, Shen S. Pathologic assessment and clinical significance of prostatic involvement by transitional cell carcinoma and prostate cancer. Urol Oncol 2008;26:481-485.

62 Amin MB, Edge S, Greene F, et al. (eds). AJCC Cancer Staging Manual, 8th edn. Springer: New York, NY, USA, 2017.

63 Osunkoya AO, Grignon DJ. Practical issues and pitfalls in staging tumors of the genitourinary tract. Semin Diagn Pathol 2012;29:154-166.

64 Chastain EC, Oliva IV, Osunkoya AO. Utility of p63 and high molecular weight cytokeratin in the distinction between urothelial carcinoma with prostatic stromal invasion and urothelial carcinoma with colonization of prostatic ducts and acini. Pathology 2012;44: 199-203.

65 Fichtenbaum EJ, Marsh WL Jr, Zynger DL. CK5, CK5/6, and double-stains CK7/CK5 and p53/CK5 discriminate in situ vs invasive urothelial cancer in the prostate. Am J Clin Pathol 2012;138:190-197.

66 Chuang AY, DeMarzo AM, Veltri RW, et al. Immunohistochemical differentiation of high-grade prostate carcinoma from urothelial carcinoma. Am J Surg Pathol 2007;31:1246-1255.

67 Amin MB, Trpkov K, Lopez-Beltran A, et al. Best practices recommendations in the application of immunohistochemistry in the bladder lesions: report from the International Society of Urologic Pathology consensus conference. Am J Surg Pathol 2014;38:e20-34.

68 Amin MB, Epstein JI, Ulbright TM, et al. Best practices recommendations in the application of immunohistochemistry in urologic pathology: report from the International Society of Urological Pathology consensus conference. Am J Surg Pathol 2014;38:1017-1022.

69 Owens CL, Epstein JI, Netto GJ. Distinguishing prostatic from colorectal adenocarcinoma on biopsy samples: the role of morphology and immunohistochemistry. Arch Pathol Lab Med 2007;131:599-603.

70 Gurel B, Ali TZ, Montgomery EA, et al. NKX3.1 as a marker of prostatic origin in metastatic tumors. Am J Surg Pathol 2010;34:1097-1105.
71 Schowinsky JT, Epstein JI. Distorted rectal tissue on prostate needle biopsy: a mimicker of prostate cancer. Am J Surg Pathol 2006;30:866-870.

72 Reinke DA, Deisch JK, Reinke DD. Gastrointestinal stromal tumor with an unusual presentation as an enlarged prostate gland: a case report and review of the literature. J Gastrointest Oncol 2016;7(Suppl 1):S71-74.

73 Huh JS, Park KK, Kim YJ, Kim SD. Diagnosis of a gastrointestinal stromal tumor presenting as a prostatic mass: a case report. World J Mens Health 2014;32:184-188.

74 Anagnostou E, Miliaras D, Panagiotakopoulos V. Diagnosis of gastrointestinal stromal tumor (GIST) on transurethral resection of the prostate: a case report and review of the literature. Int J Surg Pathol 2011;19:632-636.

75 de la Roza G, Naqvi A, Clark K. Gastrointestinal stromal tumors presenting as a prostatic mass. Can J Urol 2009;16:4502-4506.

76 Dickson BC, Srigley JR, Pollett AF, et al. Rectal gastrointestinal stromal tumor mimicking a primary prostatic lesion. Can J Urol 2008;15:4112-4114.

77 Herawi M, Montgomery EA, Epstein JI. Gastrointestinal stromal tumors (GISTs) on prostate needle biopsy: a clinicopathologic study of 8 cases. Am J Surg Pathol 2006;30:1389-1395.

78 Motley RC, Utz DC, Farrow GM, et al. Testicular seminoma metastatic to the prostate. J Urol 1986;135: 801-802.

79 Sagalowsky AI, McConnell JD, Admire R. Uncommon sites of recurrent seminoma and implications for therapy. Cancer 1986;57:1060-1065.

80 Arai Y, Watanabe J, Kounami T, et al. Retroperitoneal seminoma with simultaneous occurrence in the prostate. J Urol 1988;139:382-383.

81 Plummer ER, Greene DR, Roberts JT. Seminoma metastatic to the prostate resulting in a rectovesical fistula. Clin Oncol (R Coll Radiol) 2000;12:229-230.

82 Farnham SB, Mason SE, Smith JA Jr. Metastatic testicular seminoma to the prostate. Urology 2005;66:195.

83 Alsharif M, Aslan DL, Jessurun J, et al. Cytologic diagnosis of metastatic seminoma to the prostate and urinary bladder: a case report. Diagn Cytopathol 2008;36:734-738.

84 Dobbs RW, Osunkoya AO, Nieh PT, et al. A rare case of solitary metastatic non-seminomatous malignant germ cell tumor to the prostate. Can J Urol 2012;19:6471-6473.

85 Torelli T, Lughezzani G, Catanzaro M, et al. Prostatic metastases from testicular non-seminomatous germ cell cancer: two case reports and a review of the literature. Tumori 2013;99:e203-207. 